\title{
A Case Report of Marfan Syndrome with Literature Review
}

\author{
Hemanth Kumar Kalla, Swarna Kumari, CH Rama Rao, MKR Parthasarathy' \\ S Surya Prakash Reddy, M Revathi \\ Department of Internal Medicine, Santhiram Medical College, Nandyal, PIN 518501, Andhrapradesh, India
}

\begin{tabular}{l} 
Article Info \\
\hline Article history: \\
Received Aug 15, 2015 \\
Revised Sep 20, 2015 \\
Accepted Oct 25, 2015 \\
\hline
\end{tabular}

\section{Keyword:}

Marfan syndrome

Revised Ghent criteria

Hydroureteronephrosis

Clinical signs

\begin{abstract}
Marfan syndrome (MFS) is a connective tissue disorder that affects multiple organ systems. Cardiovascular, ocular, and skeletal abnormalities are cardinal features of the syndrome. Its incidence is among the highest of any heritable disorder.Most patients who have Marfan syndrome are usually diagnosed incidentally when they present for a routine physical examination for various reasons. The purpose of this paper is to provide a review of the literature, as well as describe a 22-year-old male with MFS and right hydroureteronephrosis diagnosed incidentally when he attended our hospital for complaints of fever and right loin pain. This case report emphasizes importance of "Revised Ghent criteria" for the diagnosis of MFS and highlights various clinical signs of MFS.
\end{abstract}

Copyright (C) 2015 Institute of Advanced Engineering and Science. All rights reserved.

\section{Corresponding Author:}

Hemanth Kumar Kalla,

Postgraduate (MD Internal Medicine),

Dept of Internal Medicine, Santhiram Medical college,

Nandyal PIN 518501, Andhrapradesh, India.

Email: kallahemanth@gmail.com

\section{INTRODUCTION}

Marfan syndrome, a rare autosomal dominant disorder was first reported way back in 1896 by a French pediatricianAntonin Marfan. The prevalence is about 1:5000 [1]. MFS was characterized by Musculoskeletal features, include stature greater than 95percentile and limbs disproportionately long for trunk size (arachnodactyly), scoliosis, pectus excavatum or carinatum, higharched palate, flat feet and marked laxity of joints. Ocular features include non -progressive upward subluxation of lens and myopia. Cardiovascular manifestations include mitral valve prolapse and dilatation of ascending aorta which lead to mitral or aortic regurgitation. The diagnosis is made based on Revised Ghent criteria for the diagnosis of Marfan syndrome (MFS) and related conditions [2].

\section{CASE PRESENTATION}

A 22 year old Indian male presented to our hospitalwith complaints of right loin pain since 3 weeks and fever since 2 weeks. His past and personal history was insignificant, but his mother had sudden death at the age of 39 years due to an undiagnosed cardiac problem. On general examination, he was lean, tall and the build of the patient is ectomorph as shown in (Figure 1). His height was $177 \mathrm{~cm}$, weight $44 \mathrm{~kg}$ and the calculated BMI $13.72(\mathrm{~kg} / \mathrm{m} 2)$. He has long arms and long slender fingers (arachnodactyly) present. His arm span to total height ratio-1.10 (>1.05), meets the MFS diagnostic criteria.His Uppersegment length- $80 \mathrm{cms,}$ Lower segment length-97cms, US/LS ratio-0.82 $(<0.85)$. There is positive thumb signor Steinberg sign as shown in (Figure 2) and positive wrist sign or walker sign as shown in (Figure 3). On examination of his oral cavity high arched palate was presentas shown in (Figure 4). There are multiple hypo pigmented macules over the hands as shown in Figures 3, 4 and also on foot of the patient. 
On examination the temperature was $37.7^{\circ} \mathrm{C}$, the pulse 102 beats per minute, the blood pressure $110 / 70 \mathrm{~mm} \mathrm{Hg}$, the respiratory rate 20 breaths per minute and the oxygen saturation $98 \%$ with room air. Cardio vascular systemic examination revealed a mid systolic click with a late systolic murmur on auscultation. There was tendernessover the right loin of the patient.

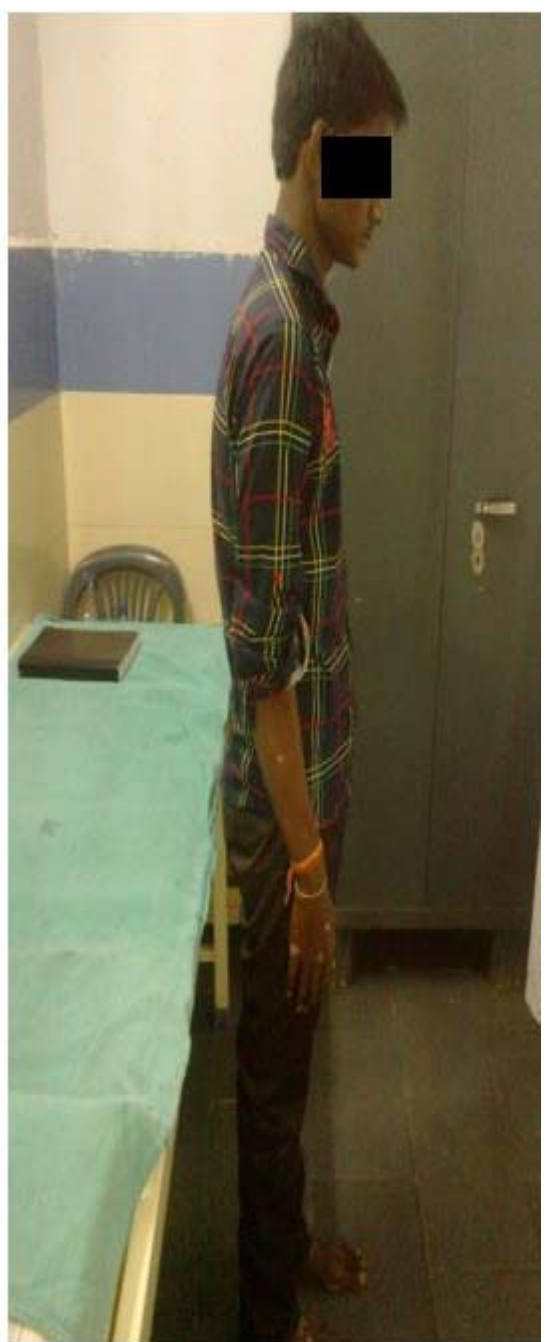

Figure 1. Showing tall and lean patient with an ectomorph build and hypo pigmented macules over fore arm

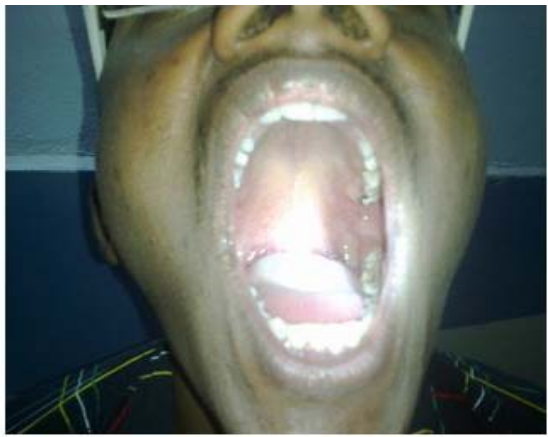

Figure 4. Showing High arched palate in this MFS patient

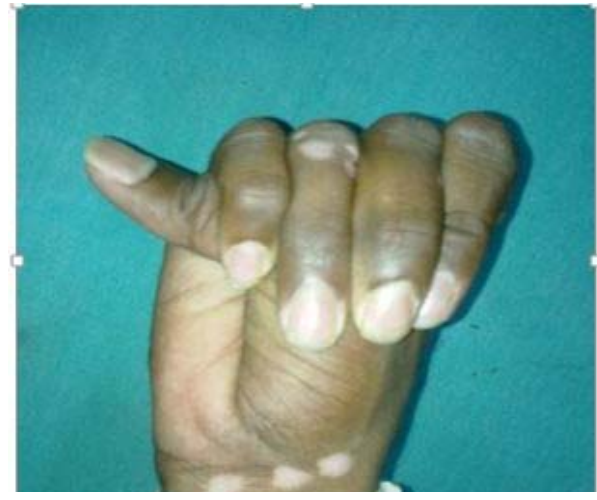

Figure 2. Showing thumb crossing the ulnar boarder of the hand, the Thumb sign or Steinberg sign

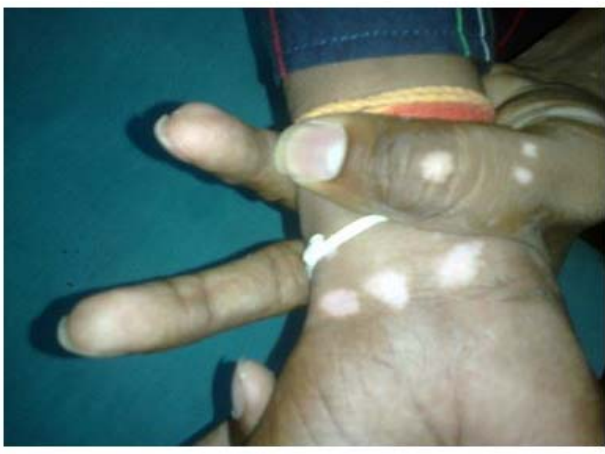

Figure 3. This image shows the Walker-Murdoch (Wrist) sign. The sign is defined as overlap of the distal phalanges of the thumb and fifth finger when encircling the opposite wrist. It is indicative of arachnodactyly or abnormally long and slender fingers

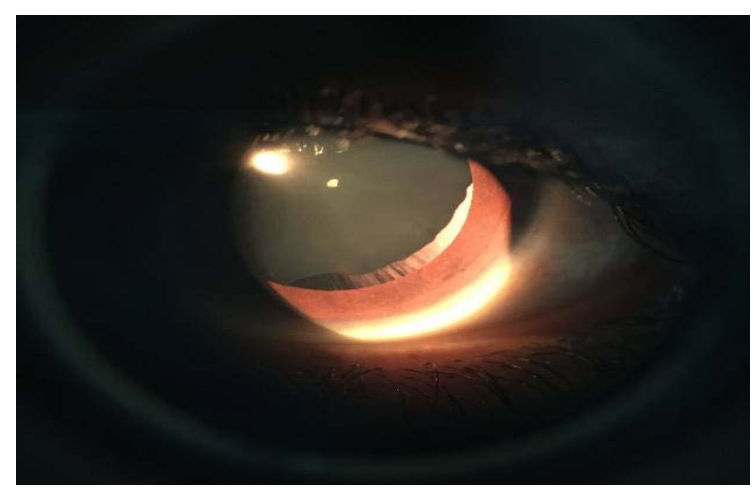

Figure 5. shows a superior and nasal subluxation of lens in the left eye( Ectopia Lentis present), on slit lamp examination 


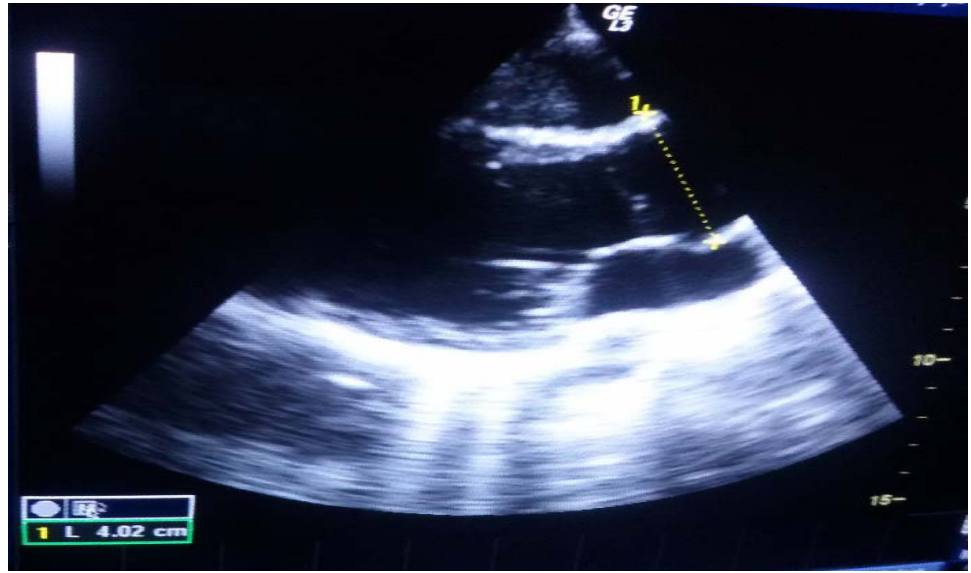

Figure 6. Shows echocardiogram in parasternal long axis view, the aortic $\operatorname{root}\left(\mathrm{A}_{\mathrm{o}}\right)$ diameter measuring $4.02 \mathrm{~cm}$ as marked above

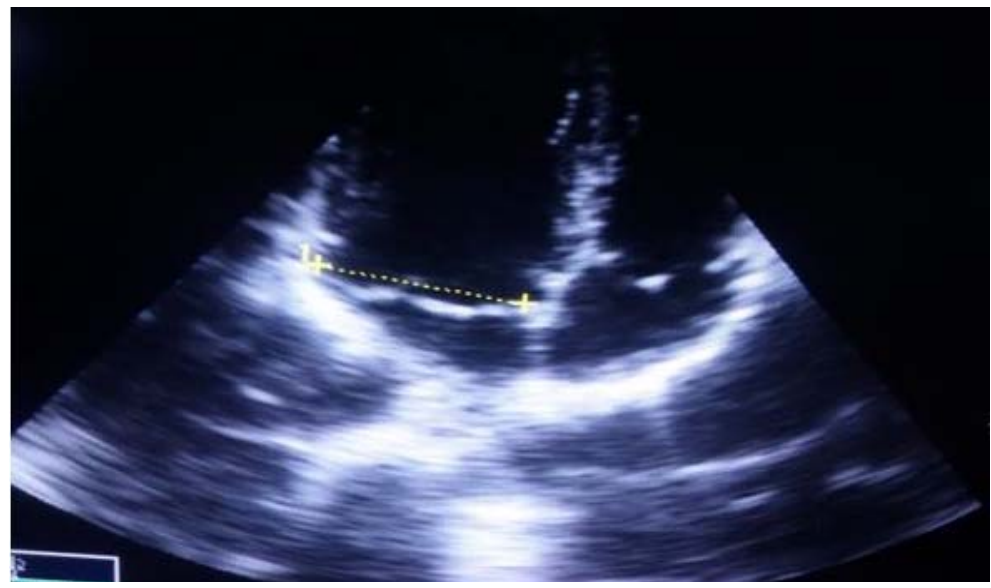

Figure 7. Shows echocardiogram in four chamber view with Mitral vavle prolapse

In our present case there was no documented family history of MFS, Ectopia Lentis (EL) was present, the $Z$ score was 3.85 ( $A o, Z \geq 2$ ) and with a systemic score of $5(\geq 7)$.

Table 1. Shows Laboratory data of the patient on the day of admission

\begin{tabular}{lcc}
\hline \multicolumn{1}{c}{ Variable } & Reference Range & $\begin{array}{c}\text { Our Admission, This } \\
\text { Hospital }\end{array}$ \\
\hline Hemoglobin(g/dl) & $13.5-17.5$ & 12.8 \\
Hematocrit(\%) & $41-53.0$ & 44 \\
White cell count(\%) & $4500-13000$ & 12,200 \\
Differential count(\%) & $40-62$ & 52 \\
Neutrophils & $27-40$ & 35 \\
Lymphocytes & $4-11$ & 8 \\
Monocytes & $0-8$ & 5 \\
Eosinophils & $0-3$ & 0 \\
Basophils & $1,50,000-4,00,000$ & $2,15,000$ \\
Platelet count( per $\left.\mathrm{mm}^{3}\right)$ & $0-15$ & 18 \\
Erythrocyte sedimentation rate(mm/hr) & $<30$ & $<30$ \\
Rheumatoid factor(IU/ml) & Non Reactive & Non Reactive \\
HIV-1 and HIV-2 antibodies & $<10$ & 12 \\
C- Reactive protein $(\mathrm{mg} /$ liter) & & \\
\hline
\end{tabular}

Based on the history of right loin pain for 3 weeks and fever for 2 weeks the patient was subjected to the following laboratory investigations to exclude renal pathology. 
Table 2. Shows Biochemistry report of the patient on the day of admission

\begin{tabular}{lcc}
\hline \multicolumn{1}{c}{ Variable } & Reference Range & $\begin{array}{c}\text { Our Admission, This } \\
\text { Hospital }\end{array}$ \\
\hline Fasting Blood Glucose $(\mathrm{mg} / \mathrm{dl})$ & $75-100$ & 84 \\
2 Hour oral glucose tolerance test $(\mathrm{mg} / \mathrm{dl})$ & $<200110$ & 134 \\
Sodium(mmol/L) & $136-146$ & 4 \\
Potassium(mmol/L) & $3.5-5$ & 104 \\
Chloride $(\mathrm{mmol} / \mathrm{L})$ & $102-109$ & 17 \\
Blood urea(mg/dl) & $7-20$ & 0.99 \\
Serum creatinine $(\mathrm{mg} / \mathrm{dl})$ & $0.5-1.5$ & \\
\hline
\end{tabular}

The laboratory data done on the day of admission as shown in Table 1 shows an elevated Erythrocyte sedimentation rate (ESR) and C-Reactive protein. The White cell count was in the upper limit as shown in Table 1. The biochemical analysis as shown in Table 2 showed no abnormality. Urine analysis showed microscopic hematuria and pyuria. Later urine culture showed the growth of Escherichia coli organisms. Next the patient was subjected to CT-Kidney, Ureters, Bladder (KUB) plain study (Figure 8).

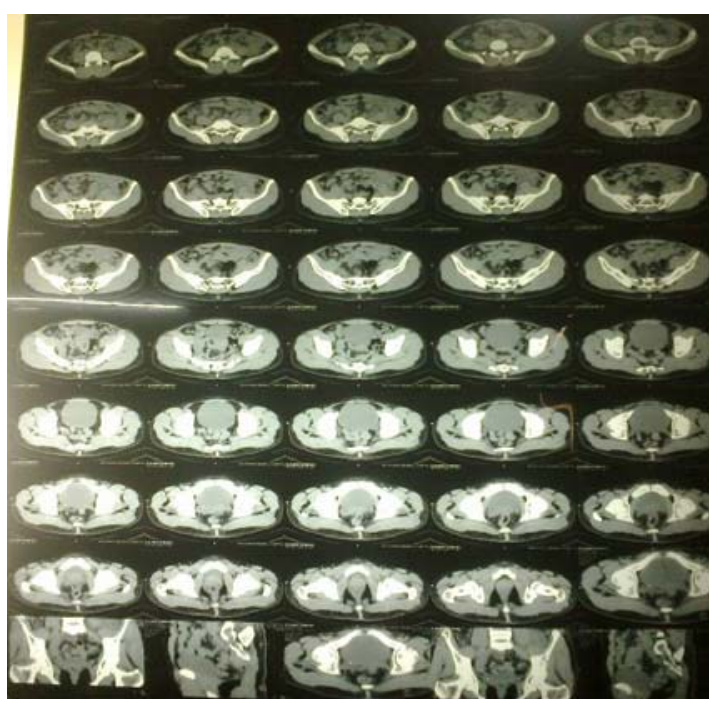

Figure 8. Shows CT-KUB PLAIN STUDY of the patient with mild hydroureteronephrosis

The CT-KUB PLAIN STUDY of the patient showed mild right hydroureteronephrosis secondary to distal ureteric $(3 \mathrm{~mm})$ and VUJ caliculi $(6 \mathrm{~mm})$ obstruction as shown in (Figure 8). Finally the patient was diagnosed with Marfan Syndrome and right hydroureteroneohrosis.

\section{TREATMENT}

On the day of admission the patient was put on analgesics for proper pain management. After the diagnosis of MFS with right hydroureteronephrosis was made, endocarditis prophylaxis was started and he was referred to urology department.The patient had undergone ureteral stent placement and recovered symptomatically. He was referred back to the department of Internal Medicine for further management regarding MFS. The patient was started on $\beta$-blocker therapy which currently remains the standard of care [3]. As the patient has moderate aortic dilatation of $3.85 \mathrm{cms}(<5 \mathrm{cms})$, both short-term and long-term $\beta$ blockade improves aortic stiffness index and elasticity in patients with modest dilatation or less, [4],[5] a benefit not observed in patients with marked dilatation [6]. Our patient was clinically asymptomatic pertaining to cardiovascular system. The patient is advised regarding moderate restriction of physical activity. Annual evaluation was offered to clinically evaluate and also with echocardiography. 


\section{DISCUSSION}

Most patients who have Marfan syndrome are usuallydiagnosed incidentally when they present for a routine physical examination for various reasons. As so in our case the patient consulted for the symptoms of right loin pain and fever, for which he was diagnosed initially with MFS.In our present case there was no documented family history of MFS, the $Z$ score was 3.85 ( Ao $Z \geq 2$ ) with Ectopia Lentis(EL) and systemic score of only 5 . According to the Revised Ghent criteria for the diagnosis of MFS a systemic score of $\geq 7$ indicates systemic involvement. The systemic score of 5 in our present case is calculated based on the following findings:

- Positive Wrist AND thumb sign -3 (Figures 2 and 3),

- Mitral valve prolapse (all types) -1 (Figure 7)

- Reduced US/LS AND increased arm/height AND no severe scoliosis -1

A diagnosis of MFS without systemic involvement was made according to the "Revised Ghent criteria", in the absence of a family history:

$$
\text { Ao }(Z \geq 2) \text { AND EL }=\text { MFS [2]. }
$$

A complete description of Revised Ghent criteria for the diagnosis of Marfan syndrome (MFS) and related conditions is given in the following Table 3. Our diagnosis was made based on the above criteria.

Table 3. Revised Ghent for the diagnosis of Marfan syndrome (MFS) and related conditions [2]

In the absence of a family history:

(1) Ao $(Z \geq 2)$ AND EL $=$ MFS

(2) Ao $(Z \geq 2)$ AND FBN1 $=$ MFS

(3) Ao $(Z \geq 2)$ AND Syst $(\geq 7$ points $)=$ MFS $^{a}$

(4) EL AND FBN1 with known Ao = MFS

EL with or without Syst AND with an FBN1 not known with Ao or no FBN1 = ELS

Ao $(Z<2)$ AND Syst $(\geq 5)$ with at least one skeletal feature without EL $=$ MASS

MVP AND Ao $(Z<2)$ AND Syst $(>5)$ without $E L=$ MVPS

In the presence of a family history:

(5) EL AND FH of MFS (as defined above) $=$ MFS

(6) Syst $(\geq 7$ points) AND FH of MFS (as defined above) $=$ MFS

(7) Ao ( $Z \geq 2$ above 20 years old, $\geq 3$ below 20 years) + FH of MFS (as defined above) $=$ MFSa

Systemic score

- Wrist AND thumb sign -3 (Wrist OR thumb sign -1 )

- Pectus carinatum deformity -2 (pectus excavatum or chest asymmetry -1 )

- Hindfoot deformity -2 (plain pes planus -1 )

- Pneumothorax -2

- Dural ectasia -2

- Protrusio acetabuli -2

- Reduced US/LS AND increased arm/height AND no severe scoliosis -1

- Scoliosis or thoracolumbar kyphosis -1

- Reduced elbow extension -1

- Facial features (3/5) -1 (dolichocephaly, enophtalmos, downslanting palpebral fissures, malar hyoplasia, retrognathia)

- Skin striae -1

- Myopia $>3$ diopters -1

- Mitral valve prolapse (all types) -1

Maximum total: 20 points; score $\geq 7$ indicates systemic involvement.

Ao, aortic diameter at the sinuses of Valsalva above indicated Z-score or aortic root dissection; EL, ectopia lentis; ELS, ectopia lentis syndrome; FBN1, fibrillin-1 mutation; FBN1 not known with Ao, FBN1 mutation that has not previously been associated with aortic root aneurysm/dissection; $F B N 1$ with known Ao, FBN1 mutation that has been identified in an individual with aortic aneurysm; FH, family history; MASS, myopia, mitral valve prolapse, borderline $(\mathrm{Z}<2)$ aortic root dilation, skeletal findings, striae; MFS, Marfan syndrome; MVPS, mitral valve prolapse syndrome; Syst, systemic score; US/LS, upper segment/lower segment ratio; Z, Z-score.

${ }^{a}$ Caveat: without discriminating features of Shprintzen-Goldberg syndrome (SGS), Loeys-Dietz syndrome (LDS) or vascular Ehlers-Danlos syndrome (vEDS) AND after TGFBR1/2, collagen biochemistry, COL3A1 testing if indicated. Other conditions/genes will emerge with time.

More than $90 \%$ of patients classified as having MFS have a mutation in the gene encoding fibrillin (FBN1, chromosome 15q15-21.3) [7], a glycoprotein that is an integral part of the connective tissue in the body.Also, a few MFS patients without mutations in the FBN1 gene have mutations in the gene for TGF- $\beta$ receptor 2 (TGF $\beta$ R2). TGF- $\beta$ was implicated in MFS following recent observation of its dysregulated signaling in fibrillin-1 deficient mice whereby antagonists of TGF- $\beta$ decreased apoptosis and rescued lung defects [8]. The high levels of circulatingTGF- $\beta$ in MFS patients [9], which incidentally ameliorated following treatment with losartan (an angiotensin II receptor blocker; ARB with TGF- $\beta$ antagonistic 
properties) [10], thus supporting TGF- $\beta$ as a therapeutic target and potential biomarker for MFS. So treatment of MFS with losartan appears to be promising based on studies in animal models and is undergoing clinical trails.

\section{CONCLUSION}

Most patients who have Marfan syndrome are usuallydiagnosed incidentally when they present for a routine physical examination for various reasons. This case report brings forth the review of various clinical signs of MFS, its diagnosis based on the Revised Ghent criteria, its management and the associated comorbid conditions.

\section{CONFLICT OF INTEREST}

The authors report no relationships that could be construed as a conflict of interest.

\section{REFERENCES}

[1] HC. Dietz, GR. Cutting, RE. Pyeritz, CL. Maslen, LY. Sakai, GM. Corson, et al., "Marfan syndrome caused by a recurrent de novo missense mutation in the fibrillin gene", Nature, vol. 352, pp. 337-339, 1991.

[2] Loeys BL., et al., J Med Genet, vol. 47, pp. 476-485, 2010. doi:10.1136/jmg.2009.072785.

[3] Pyeritz RE., "Marfan syndrome and related disorders", In: Rimoin DL., Connor JM., Pyeritz RE., Korf BR., eds., Emery and Rimoin's Principles and Practice of Medical Genetics", 5th ed. London, UK, Churchill Livingstone, vol 3, pp. 3579-3624, 2007.

[4] Groenink M., DeRoos A., Mulder BJM., Spaan JAE., VanDerWall EE., "Changes in aortic distensibility and pulse wave velocity assessed with magnetic resonance imaging following beta-blocker therapy in the Marfan syndrome", Am J Cardiol, vol. 82,pp. 203-208, 1998.

[5] Rios AS., Silber EN., Bavishi N., Varga P., Burton BK., Clark WA., Denes P., "Effect of long-term $\beta$-blockade on aortic root compliance in patients with Marfan syndrome”, Am Heart J., vol. 137, pp. 1057-1061, 1999.

[6] Yin FCP., Brin KP., Ting CT., Pyeritz RE., “Arterial hemodynamic indexes in Marfan's syndrome”, Circulation, vol. 79, pp. 854-862, 1989

[7] Pyeritz RE., "Disorders of fibrillins and microfibrilogenesis: marfan syndrome, MASS phenotype, Contractural arachnodactyly and related conditions", In: Rimoin DL., Connor JM., Pyeritz RE., editors, "Emery and Rimoin's principles and practice of medical genetics", 3rd ed, New York, Churchill Livingstone, pp. 1027-66, 1997.

[8] ER. Neptune, PA. Frischmeyer, DE. Arking, L. Myers, TE. Bunton, B. Gayraud, et al., "Dysregulation of TGF-beta activation contributes to pathogenesis in Marfan syndrome", Nat. Genet., vol. 33, pp. 407-411, 2003.

[9] R. Franken, AW. den Hartog, V. de Waard, L. Engele, T. Radonic, R. Lutter, et al., "Circulating transforming growth factor-beta as a prognostic biomarker in Marfansyndrome”, Int. J. Cardiol., vol. 168, pp. 2441-2446, 2013.

[10] P. Matt, F. Schoenhoff, J. Habashi, T. Holm, C. Van Erp, D. Loch, et al., "Circulating transforming growth factorbeta in Marfan syndrome", Circulation, vol. 120, pp. 526-532, 2009. 